\title{
Rapid thermal annealing of FePt nanoparticles
}

\author{
Kazuaki Yano, Vikas Nandwana, Narayan Poudyal, Chuan-Bing Rong, and J. Ping Liu \\ Department of Physics, University of Texas at Arlington, Arlington, Texas 76019, USA
}

(Received 21 January 2008; accepted 2 May 2008; published online 11 July 2008)

\begin{abstract}
We report a systematic study on rapid thermal annealing (RTA) of FePt nanoparticles. FePt particles with an average size of $8 \mathrm{~nm}$ were synthesized by a chemical solution method, and then annealed using RTA and conventional furnace annealing (FA). It was observed that FePt nanoparticles can be transformed from disordered $A 1$ phase to ordered $L 1_{0}$ phase at $650{ }^{\circ} \mathrm{C}$ for $10 \mathrm{~s}$ using RTA, which is much shorter than the time needed for FA. The transmission electron microscopy and $\mathrm{X}$-ray diffraction studies have revealed that the particle agglomeration and grain growth in the RTA treated samples are much less than in the FA treated samples. A linear correlation between the coercivity and the square root of the treatment time $\sqrt{t}$ was observed in the RTA treated samples, which implies that the phase transition is related to atomic diffusion of Fe atoms from Fe-rich shells into the Pt-rich cores. (C) 2008 American Institute of Physics. [DOI: 10.1063/1.2953078]
\end{abstract}

\section{INTRODUCTION}

FePt nanoparticles have drawn great attention in the past years due to the potential applications in many areas including data storage, permanent magnets, and biomedical technology. ${ }^{1-7}$ High uniaxial magnetocrystalline anisotropy of the $L 1_{0} \mathrm{FePt}$ phase is one of the key properties for those applications. ${ }^{8}$ Unfortunately, as-synthesized FePt particles take a disordered $A 1$ structure which has vanishingly small magnetocrystalline anisotropy. Therefore postsynthesis annealing is necessary to transform the disordered $A 1$ phase to the ordered $L 1_{0}$ phase. However, the heat treatment always causes sintering and agglomeration of FePt nanoparticles and leads to destruction of monodispersion of the nanoparticles. This undesired morphology change is a severe problem for many applications which require a morphology control in the nanostructured materials. Many studies have been done to solve the problem and to produce monodisperse FePt nanoparticles. For example, the salt-matrix annealing is an effective method to produce monodisperse $L 1_{0}$ structured $\mathrm{FePt}$ nanoparticles by using salts as the separating media. ${ }^{9-13}$ Coating of high-melting-point materials on FePt particles can also be a good technique to prevent agglomeration and sintering. ${ }^{14,15}$

Controlling annealing time is another option to reduce the sintering by limiting interdiffusion between nanoparticles. Recently, the rapid thermal annealing (RTA) technique has been applied for magnetic materials with which samples can be heated to high temperature in a time scale of seconds. ${ }^{16-18}$ Zeng et al. ${ }^{19}$ reported that the chemical ordering of $4 \mathrm{~nm} \mathrm{FePt}$ particles starts at the temperature of $400{ }^{\circ} \mathrm{C}$ by using RTA, which is lower compared to conventional furnace annealing (FA) and a short annealing time results in reduced sintering of particles. However, there has not been an in-depth study reported of the correlation between magnetic hardening and morphology change in RTA treated FePt nanoparticles. In this paper, we report a systematic

\footnotetext{
a) Author to whom correspondence should be addressed; electronic mail: pliu@uta.edu.
}

study on effects of annealing temperature and time on the $L 1_{0}$ phase formation and morphology change of FePt nanoparticles induced by RTA.

\section{EXPERIMENTS}

$8 \mathrm{~nm}$ FePt nanoparticles were prepared via chemical solution route consisting of reduction in $\mathrm{Pt}(\mathrm{acac})_{2}$ and decomposition of $\mathrm{Fe}(\mathrm{CO})_{5}$ under argon gas flow. To obtain $8 \mathrm{~nm}$ particles instead of $4 \mathrm{~nm}$ ones, the synthesis procedure is slightly different from the method used in Ref. 1 In a typical procedure, $0.5 \mathrm{mmol}$ of $\mathrm{Pt}(\mathrm{acac})_{2}$ and $10 \mathrm{ml}$ of octyl ether were added in a $125 \mathrm{ml}$ flask with a magnetic stir bar. After purging argon gas for $20 \mathrm{~min}$, the flask was heated up to $110^{\circ} \mathrm{C}$ for $10 \mathrm{~min}$. After the Pt precursor dissolved completely at $110{ }^{\circ} \mathrm{C}, 0.4 \mathrm{mmol}$ of oleic acid and $0.4 \mathrm{mmol}$ oleyl amine were added into the flask followed by $0.75 \mathrm{mmol}$ of $\mathrm{Fe}(\mathrm{CO})_{5}$. The flask was then heated up to $300{ }^{\circ} \mathrm{C}$ and refluxed for $1 \mathrm{~h}$. After $\mathrm{Fe}(\mathrm{CO})_{5}$ was added, the solution color changed from transparent yellow to black which suggests the formation of FePt nanoparticles. After the reflux, the flask was cooled down to room temperature under argon flow. It should be noted that cubic particles were formed instead of spherical particles, as reported in Ref. 1, due to the difference in the synthesis procedure (e.g., 1,2hexadecanediol was not used). The cubic shape may also be explained by the molecular structure of the solvent. ${ }^{20}$ The black particles were precipitated after adding $35 \mathrm{ml}$ of ethanol and separated by centrifugation at $6000 \mathrm{rpm}$ for $20 \mathrm{~min}$. The precipitated particles were then dispersed in $10 \mathrm{ml}$ of hexane. In order to remove the extra surfactant completely, the centrifugation was repeated twice. Final products were dispersed in $10 \mathrm{ml}$ hexane.

The dispersed FePt particles were deposited on a Si substrate and annealed at different conditions using the RTA facility (Modular Process Technology model RTP-600S rapid thermal processing system) and a FA facility under forming gas $\left(93 \% \mathrm{Ar}+7 \% \mathrm{H}_{2}\right)$ flow after evaporating hexane at room temperature. The magnetic measurements were carried out using alternating gradient magnetometer and superconduct- 


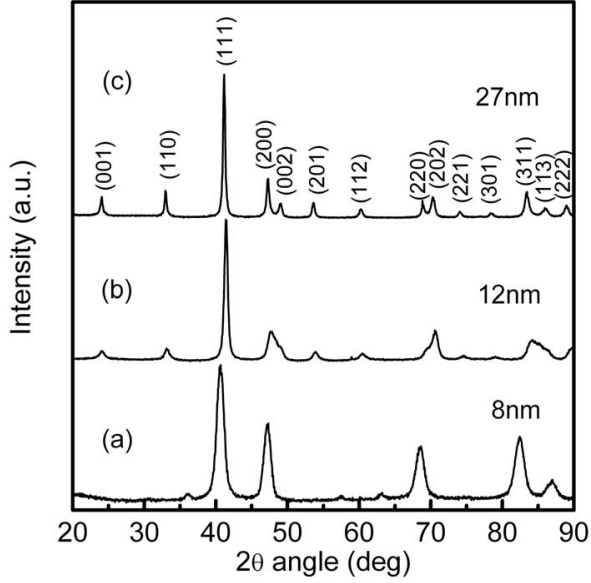

FIG. 1. XRD patterns of FePt nanoparticles of (a) as-synthesized, (b) annealed at $650{ }^{\circ} \mathrm{C}$ for $5 \mathrm{~s}$ by RTA, and (c) annealed at $650{ }^{\circ} \mathrm{C}$ for $10 \mathrm{~min}$ by FA. The average grain sizes are (a) $8 \mathrm{~nm}$, (b) $12 \mathrm{~nm}$, and (c) $27 \mathrm{~nm}$, respectively.

ing quantum interference device magnetometer with a magnetic field up to $7 \mathrm{~T}$. The transmission electron microscopy (TEM) was used for morphology observations. The composition of the particles (around $\mathrm{Fe}_{50} \mathrm{Pt}_{50}$ ) was checked by energy dispersive $\mathrm{X}$-ray spectroscopy. X-ray diffraction (XRD) was used to determine the phase transition of FePt nanoparticles with a $\mathrm{CuK}_{\alpha}$ radiation $(\lambda=1.5405 \AA)$.

\section{RESULTS AND DISCUSSIONS}

Heat treatments of the as-synthesized FePt nanoparticles lead to formation of the $L 1_{0}$ phase. It is important to know how short the phase transition from $A 1$ to $L 1_{0}$ is needed. Advantages of RTA include fast heating/cooling and controllable short annealing time, compared with conventional FA. Figure 1 shows the XRD patterns of the as-synthesized and the as-annealed FePt particles by using RTA and FA. In Fig. 1(a), the strongest (111) peak at $40.5^{\circ}$ corresponds to the face-centered cubic structure obtained from the randomly oriented particles. The grain size calculated by Scherrer's equation $^{21}$ is around $8 \mathrm{~nm}$. As shown in Fig. 1(b), the (111) peak of the RTA treated FePt nanoparticles shifted to $41^{\circ}$ and the superlattice (001) and (110) peaks showed up after the annealing, indicating the formation of the $L 1_{0}$ ordered phase within $5 \mathrm{~s}$ at $650{ }^{\circ} \mathrm{C}$. The particle size of $650{ }^{\circ} \mathrm{C} \times 5 \mathrm{~s}$ RTA treated particles is calculated as $12 \mathrm{~nm}$ compared to $27 \mathrm{~nm}$ for $650{ }^{\circ} \mathrm{C} \times 10 \mathrm{~min}$ FA treated particles [Figure 1(c)]. It should be noted that the XRD analysis gives only grain size instead of particle size.

Figure 2 shows the grain size dependence on annealing time for RTA and FA at $650{ }^{\circ} \mathrm{C}$. The grain size increases with annealing time for both annealing methods. However, the "saturation" grain size of $17 \mathrm{~nm}$ for RTA is much smaller than that of the size of $30 \mathrm{~nm}$ for FA, indicating that RTA leads to much less particle sintering and grain growth. As we will see later, the grain growth saturation is accompanied by the magnetic hardening saturation.

Morphology observations have directly shown how the heat treatments affect the particle sintering and grain growth.

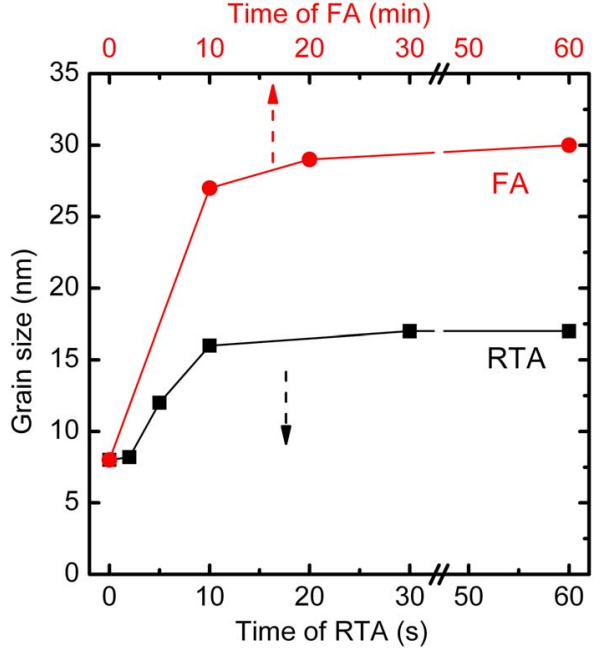

FIG. 2. (Color online) The grain size as a function of annealing time at $650{ }^{\circ} \mathrm{C}$ for RTA and FA treated samples.

Figure 3 shows the TEM images of as-synthesized FePt particles and their morphology changes after different annealing processing. Here, $30 \mathrm{~s}$ RTA treated samples and $1 \mathrm{~h}$ FA treated samples were compared since they have almost the same coercivity (as shown in Fig. 4). It was seen that the as-synthesized FePt particles have a size around $8 \mathrm{~nm}$ with cubic shape, as we mentioned earlier. Figure 3(b) shows that the FePt particles by RTA treatment at $550{ }^{\circ} \mathrm{C}$ for $30 \mathrm{~s}$ are quite similar to the as-synthesized particles except few bigger particles. It was found that there is less sintering and agglomeration in the RTA treated particles compared to the FA treated samples. The dispersion can be maintained even at temperatures as high as $650^{\circ} \mathrm{C}$, as shown in Fig. 3(c). However, the cubic shape has been changed to spherical shape upon the annealing which may be caused by diffusion on the particle surface which led to reduction in surface energy. In contrast, severe sintering was observed in FA treated particles. The particle size increased to $50-100 \mathrm{~nm}$ and the monodispersion was completely destroyed, as shown in Figs 3(d) and 3(e), although the annealing temperatures were the same as in the RTA $\left(550\right.$ and $\left.650^{\circ} \mathrm{C}\right)$. It can also be seen from the contrast difference in individual particles that the as-synthesized single crystalline particles had sintered to form polycrystalline particles. The morphology difference between the RTA and the FA treated samples is mainly caused by the annealing time difference in the RTA and the FA. In addition, the heating/cooling rate can be another reason for the difference. It should be noted that the annealing effect on the morphology change of the two-dimension monolayer particles is different from that of the multilayered samples on a solid substrate since the diffusion in a multilayer is in three dimension, which explains the small difference in grain size results obtained from the TEM and the XRD analyses.

The degree of long-range chemical order of $L 1_{0}$ phase can be evaluated by calculating the chemical ordering parameter $S$ using the equation ${ }^{11,22}$ 


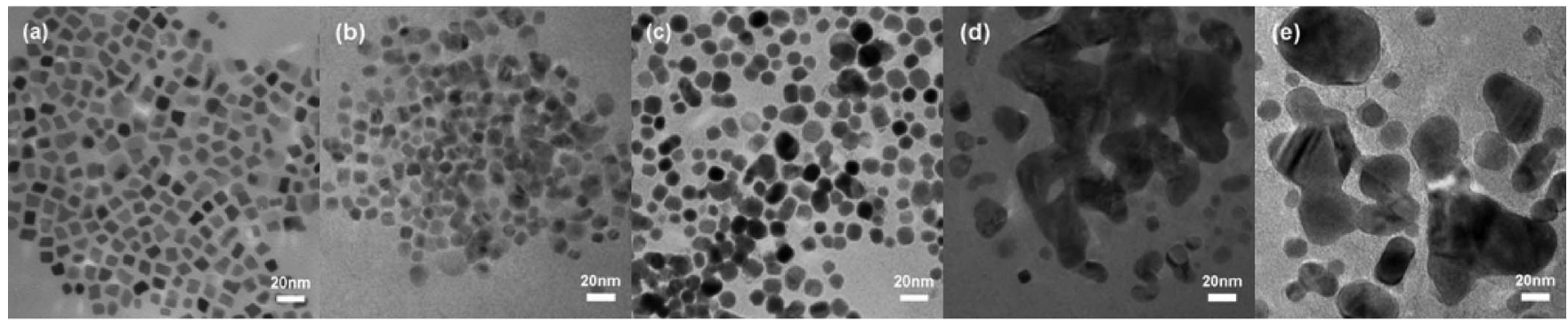

FIG. 3. TEM images of $8 \mathrm{~nm}$ FePt nanoparticles: (a) as-synthesized particles, (b) RTA treated at $550{ }^{\circ} \mathrm{C}$ for $30 \mathrm{~s}$, (c) RTA treated at $650{ }^{\circ} \mathrm{C}$ for $30 \mathrm{~s}$, (d) furnace annealed at $550{ }^{\circ} \mathrm{C}$ for $1 \mathrm{~h}$, and (d) furnace annealed at $650{ }^{\circ} \mathrm{C}$ for $1 \mathrm{~h}$.

$$
S \cong 0.85\left[\frac{I_{001}}{I_{002}}\right]^{1 / 2},
$$

where $I_{001}$ and $I_{002}$ are the integrated intensities of the (001) and (002) diffraction peaks from the XRD patterns, respectively. To monitor the formation of $L 1_{0}$ phase induced by the heat treatments, $\mathrm{FePt}$ nanoparticles were annealed at $650^{\circ} \mathrm{C}$ for different times by RTA. Figure 4 compares the dependence of $S$ and coercivity on annealing time for RTA treated samples. It was found that high $S$ value about 0.97 was achieved by RTA at $650{ }^{\circ} \mathrm{C}$ for only $10 \mathrm{~s}$. The further RTA treatment, however, does not change $S$ anymore, indicating that the transformation from A1 to $L 1_{0}$ phase of the $\mathrm{FePt}$ nanoparticles was completed within $10 \mathrm{~s}$ at $650{ }^{\circ} \mathrm{C}$. Since the magnetic hardening of the FePt nanoparticles is closely related to the chemical ordering parameter, the effect of annealing time on coercivity is similar to that on the chemical ordering parameter, although coercivity is not solely determined by crystalline parameters (it is also related to morphology of the particles). The RTA induced magnetic hardening within several seconds for other magnetic materials was also observed and discussed in other reports. ${ }^{23-25}$ This phenomenon may be explained by a lowered phase transition temperature in RTA treated samples. Figure 5 shows the demagnetization curve of the $8 \mathrm{~nm} \mathrm{FePt}$ particles annealed at $650{ }^{\circ} \mathrm{C}$ for $10 \mathrm{~s}$ by RTA as an example. It was found that the squareness of the demagnetization curve is also very good even though the sample was heated for only $10 \mathrm{~s}$. The energy product of the particles is around 12.7 MG Oe.

Since the magnetic hardening process of FePt particles is

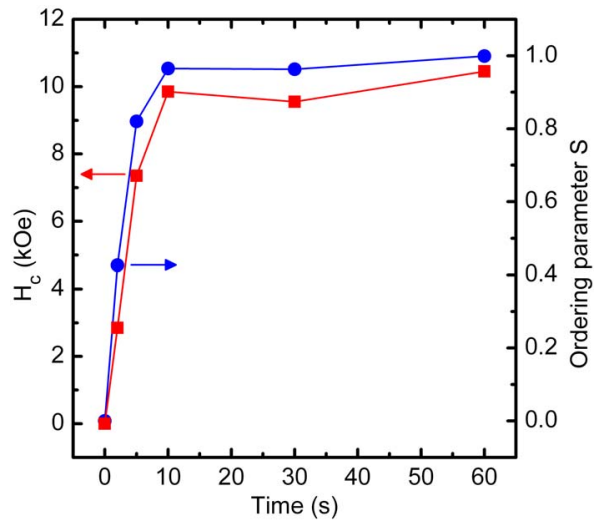

FIG. 4. (Color online) The annealing time dependence of chemical ordering parameter and coercivity for RTA performed at $650^{\circ} \mathrm{C}$. related to the atomic rearrangement from disordered $A 1$ phase to ordered $L 1_{0}$ phase, it is reasonable to correlate an atomic diffusion process to the annealing process. In order to understand the magnetic hardening rate at various annealing temperatures, RTA was conducted at different temperatures for different time for the $8 \mathrm{~nm} \mathrm{FePt}$ particles. Figure 6(a) shows the coercivity dependence on annealing time at different temperatures. It was found that the coercivity increases with increasing annealing time and temperature. The $H_{c}$ reaches its saturated value of $10 \mathrm{kOe}$ within $60 \mathrm{~s}$ if the temperature is above $600{ }^{\circ} \mathrm{C}$. However, for $500{ }^{\circ} \mathrm{C}$ annealing, the $H_{c}$ does not saturate even after $300 \mathrm{~s}$ and this particular sample has the ordering parameter of only 0.58 , which suggests that the $A 1$ to $L 1_{0}$ phase transformation cannot be completed at $500{ }^{\circ} \mathrm{C}$ for a short annealing time by RTA.

In addition, correlation between the coercivity and the square root of treatment time $\sqrt{t}$ of RTA treated samples was observed, as shown in Fig. 6(b). It is well known that the diffusion coefficient $D$ is expressed as

$$
D=D_{0} \exp \left(\frac{E}{k T}\right),
$$

where $D_{0}$ is a constant $\left(\mathrm{cm}^{2} \mathrm{~s}^{-1}\right), E$ is the activation energy $(\mathrm{eV}), T$ is the temperature $(\mathrm{K})$ and $k$ is Boltzmann's constant $\left(k=8.617 \times 10^{-5} \mathrm{eV} \mathrm{K}^{-1}\right)$. Calorimetric studies of the $A 1$ to $L 1_{0}$ transition in FePt particles have revealed that the activation energy of phase transformation is about $1.0-1.7 \mathrm{eV}^{26-28} \mathrm{~A}$ diffusion distance $x$ is given as

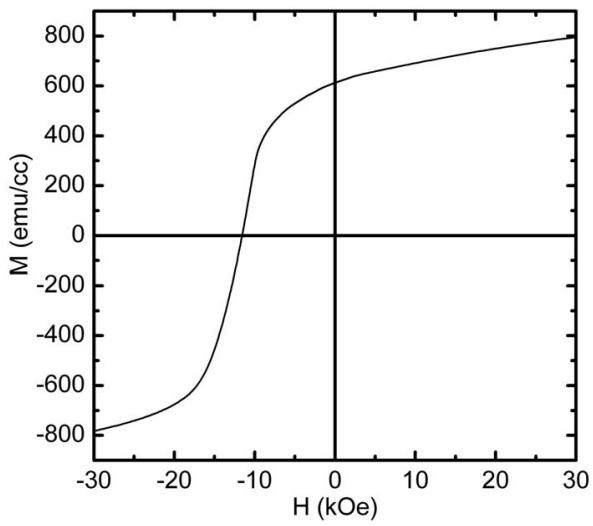

FIG. 5. Demagnetization curves of $8 \mathrm{~nm} \mathrm{FePt}$ particles annealed at $650^{\circ} \mathrm{C}$ for different times. 

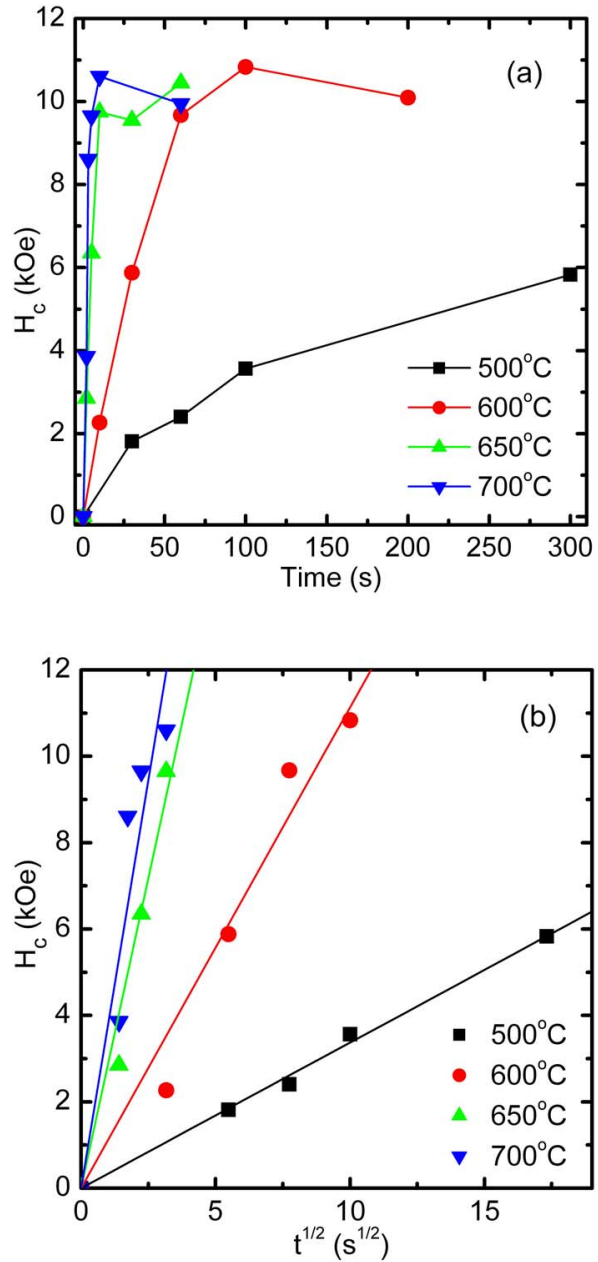

FIG. 6. (Color online) The relationship between the coercivity and annealing time at different temperatures with (a) the linear time scale and (b) the square root of time scale.

$$
x=\sqrt{D t} .
$$

This correlation between diffusion distance and $\sqrt{t}$ is similar to the correlation between the $H_{c}$ and $\sqrt{t}$ observed from Fig. 6(b), which implies that the phase transition and magnetic hardening process are related to the interdiffusion of $\mathrm{Pt}$ and $\mathrm{Fe}$ atoms between the Pt-rich cores and the Fe-rich shells. ${ }^{26}$ However, the mechanism behind the correlation between the diffusion distance and the annealing time needs to be further understood. An investigation is underway to further study the relationship between the activation energy required for the magnetic hardening and the phase transformation in $\mathrm{FePt}$ nanoparticles using a combination of RTA and calorimetric measurements.

\section{CONCLUSION}

As-synthesized FePt particles with an average size of $8 \mathrm{~nm}$ were heat treated using RTA at various temperatures for different times. The FePt nanoparticles can be transformed from disordered $A 1$ phase to ordered $L 1_{0}$ phase in a short time by RTA treatment. The microstructure observation has revealed that the average grain size of RTA treated samples is substantially smaller than that of the FA treated samples. A linear correlation between the coercivity and the square root of treatment time $\sqrt{t}$ was observed in the RTA treated samples.

\section{ACKNOWLEDGMENTS}

This work was supported by ONR/MURI under Grant No. N00014-05-1-0497, DoD/DARPA through ARO under Grant No. DAAD 19-03-1-0038, and USHIO Inc. This work was also supported by Center of Nanostructured Materials and Characterization Center for Materials and Biology at the University of Texas at Arlington.

${ }^{1}$ S. Sun, C. B. Murray, D. Weller, L. Folks, and A. Moser, Science 287, 1989 (2000).

${ }^{2}$ H. Zeng, J. Li, J. P. Liu, Z. L. Wang, and S. H. Sun, Nature (London) 420 , 395 (2002).

${ }^{3}$ S. Sun, Adv. Mater. (Weinheim, Ger.) 18, 393 (2006).

${ }^{4}$ C. B. Rong, H. W. Zhang, R. J. Chen, S. L. He, and B. G. Shen, J. Magn. Magn. Mater. 302, 126 (2006).

${ }^{5}$ C. B. Rong, V. Nandwana, N. Poudyal, Y. Li, J. P. Liu, Y. Ding, and Z. L. Wang, J. Phys. D: Appl. Phys. 40, 712 (2007).

${ }^{6}$ C. B. Rong, V. Nandwana, N. Poudyal, J. P. Liu, M. E. Kozlov, R. H. Baughman, Y. Ding, and Z. L. Wang, J. Appl. Phys. 102, 023908 (2007).

${ }^{7}$ C. B. Rong and J. P. Liu, Appl. Phys. Lett. 90, 222504 (2007).

${ }^{8}$ O. Gutfleisch, J. Lyubina, K.-H. Müller, and L. Schultz, Adv. Eng. Mater. 7, 208 (2005).

${ }^{9}$ K. Elkins, D. Li, N. Poudyal, V. Nandwana, Z. Q. Jin, K. H. Chen, and J. P. Liu, J. Phys. D: Appl. Phys. 38, 2306 (2005).

${ }^{10}$ D. Li, N. Poudyal, V. Nandwana, Z. Q. Jin, K. Elkins, and J. P. Liu, J. Appl. Phys. 99, 08E911 (2006).

${ }^{11}$ C. B. Rong, D. R. Li, V. Nandwana, N. Poudyal, Y. Ding, Z. L. Wang, H. Zeng, and J. P. Liu, Adv. Mater. (Weinheim, Ger.) 18, 2984 (2006).

${ }^{12}$ C. B. Rong, N. Poudyal, G. S. Chaubey, V. Nandwana, R. Skomski, Y. Q. Wu, and M. J. Kramer, and J. P. Liu, J. Appl. Phys. 102, 043913 (2007).

${ }^{13}$ C. B. Rong, N. Poudyal, G. S. Chaubey, V. Nandwana, Y. Z. Liu, Y. Q. Wu, M. J. Kramer, M. E. Kozlov, R. H. Baughman, and J. P. Liu, J. Appl. Phys. 103, 07E131 (2008).

${ }^{14}$ S. Yamamoto, Y. Morimoto, T. Ono, and M. Takano, Appl. Phys. Lett. 87, 032503 (2005).

${ }^{15}$ N. Caiulo, C. H. Yu, K. M. K. Yu, C. C. H. Lo, W. Oduro, B. Thiebaut, P. Bishop, and S. C. Tsang, Adv. Funct. Mater. 17, 1392 (2007).

${ }^{16}$ Z. Q. Jin, B. Z. Cui, J. P. Liu, Y. Ding, Z. L. Wang, and N. N. Thadhani, Appl. Phys. Lett. 84, 4382 (2004).

${ }^{17}$ Z. Q. Jin, K. H. Chen, J. Li, H. Zeng, S. F. Cheng, J. P. Liu, Z. L. Wang, and N. N. Thadhani, Acta Mater. 52, 2147 (2004),.

${ }^{18}$ Z. Q. Jin and J. P. Liu, J. Phys. D: Appl. Phys. 39, R227 (2006).

${ }^{19}$ H. Zeng, S. Sun, R. L. Sandstrom, and C. B. Murray, J. Magn. Magn. Mater. 266, 227 (2003).

${ }^{20}$ V. Nandwana, K. E. Elkins, N. Poudyal, G. S. Chaubey, K. Yano, and J. P. Liu, J. Phys. Chem. C 111, 4185 (2007).

${ }^{21}$ B. D. Cullity and S. R. Stock, X-ray Diffraction, 3rd ed., (Prentice-Hall, Englewood Cliffs, NJ, 2001), p. 170.

${ }^{22}$ J. A. Christodoulides, P. Farber, M. Daniil, H. Okumura, G. C. Hadjipanayis, V. Skumryev, A. Simopoulos, and D. Weller, IEEE Trans. Magn. 37, 1292 (2001).

${ }^{23}$ K. T. Chu, Z. Q. Jin, V. M. Chakka, and J. P. Jiu, J. Phys. D: Appl. Phys. 38, 4009 (2005).

${ }^{24}$ Z. Q. Jin, V. M. Chakka, Z. L. Wang, J. P. Liu, and R. D. Ott, JOM 58, 46 (2006).

${ }^{25}$ K. Aimuta, K. Nishimura, S. Hashi, and M. Inoue, IEEE Trans. Magn. 41, 3898 (2005)

${ }^{26}$ M. Rennhofer, B. Sepiol, M. Sladecek, D. Kmiec, S. Stankov, G. Vogl, M. Kozlowski, R. Kozubski, A. Vantomme, J. Meersschaut, R. Rüffer, and A. Gupta, Phys. Rev. B 74, 104301 (2006).

${ }^{27}$ F. E. Spada, F. T. Parker, C. L. Platt, and J. K. Howard, J. Appl. Phys. 94, 5123 (2003).

${ }^{28}$ J. Lyubina, O. Gutfleisch, R. Skomski, K.-H. Muller, and L. Schultz, Scr. Mater. 53, 469 (2005). 